\title{
A Voz da Academia (*)
}

\section{Mario Romeu de Lucca}

Éramos no passado...

Vislumbrávamos, ao adentrarmos a Academia, todas as glórias acenadas aos moços pela vida, que neles se inicia. repleta de esperanças.

Pressentíamos, naquele longínquo 1937, que da Faculdade havíamos de fazer a nossa morada de todos os dias em anos subsequentes, que nela havíamos de viver largo. tempo, sentindo-lhe toda a fôrça da tradição e todo o estímulo que a sua história faz nascer na alma dos jovens.

Percebíamos, com aparente clareza, o significado da Academia na vida nacional e nos orgulhávamos de ostentar perante o mundo, que a nossos olhos bastante se alargara em âmbito, o título desvanecedor: Acadêmico de Direito.

As lições que da autoridade dos mestres recebíamos, gravavam-se indeléveis na "tabula rasa" da inteligência e a pouco e pouco iam influenciando o coração, fazendo nele nascer a amizade que dedicamos àqueles que nos ensinaram o Direito.

A presença da Faculdade realizava em nós a ação catalítica imprescindivel para que nos entregássemos, de corpo e alma, a novos ideais. A ela acorríamos, sedentos de saber, procurando curiosamente as idéias que esvoaçavam aladas. e puras, por entre as monacais Arcadas sob cuja proteção pressentíamos, por instantes embora fugazes, a veia da pe-

(*) Discurso proferido, a 5 de janeiro de 1942 , como orador da turma de bachareis de 1941, na solenidade da colação de gráu realizada no Teatro Municipal. 
rene caudal que, através das idades e das tribulações da História, passa pela humanidade e fecunda o espírito.

Os princípios teóricos da ciência jurídica, ouvíamo-los diuturnamente, jorrados com abundância do alto das venerandas cátedras, cuja experiência nos advertia a que não nos iludíssemos com o sôpro transitório das psicoses coletivas, nas quais o Direito é vilipendiado e escarnecido.

Eramos no passado...

Impelia-nos ao estudo o amor ao jurídico, porque no Direito víamos a garantia da ordem estabelecida, nele e por ele a manutenção da Paz e a continuidade da Harmonia sem as quais não póde a sociedade humana existir e progredir.

Julgávamo-nos senhores do futuro trazendo, ao sabor da nossa irreverente vontade, o destino da Pátria, do qual dispúnhamos a talante nosso.

Embriavavam-nos de contentamento as festas acadêmicas e assentíamos vibrantemente com os oradores, quando eles, invocando o pretérito faustoso da escola-convento, afirmavam-na ser o relicário das mais santas e nobres tradições da nacionalidade.

Os nossos sonhos diluiam, com as suas claridades, todas as sombras com que a realidade procurava diminuir-lhes o viço do esplendor.

Duvidávamos, com o Candide, de Voltaine, que não pudesse o milhafre sofrear o instinto de rapina, diante da inocência imbele da columba. Pangloss jamais se nos apresentara destituido de razões ao aplicar a otimista máxima leibniziana. Não nascidos ainda para os revezes da existência, o bem e o mal se nos afiguravam termos de aleatória aplicabilidade social, ante a insignificância da tragédia humana, quando posta em relação com o eterno. A maneira do fidalgo de La Mancha, trazíamos nalma, como Dulcinéia, a Liberdade. Os magnos problemas do espírito apresentavam-se como questões que pairassem aquém dos cuidados da nossa cogitação. Muito a gosto, concordávamos com Carrel, em que o homem é um enigma para as suas próprias pesquisas: conjunto de átomos aprisionados num 
recipiente de barro, cujo destino é morrer. Egocentricamente, fazíamos girar o mundo em torno de nosso ser individual, que sobrepúnhamos ao ser social - sistema de hábitos, de sentimentos e idéias, de crenças e tradições que na concepção de Émile Durk heim exprimem, em nós, a coletividade.

Líamos Nietzsche e não nos repugnavam as excentricidades de Zaratustra. Sem havermos sentido as dificuldades cruciantes dos escarpados, encastelávamo-nos no cimo da montanha, em torre de marfim, para rirmos, como o superhomem do filósofo prussiano, de todos os dramas do homem.... Distantes do virtuoso meio-termo do Estagírita, nossas atitudes traziam, no bojo de seus exageros, a mesma inscrição do templo de Apolo em Delfos: "Panta agan" tudo em excesso!

- Éramos Gedeões derrotando milhares de madianitas, apenas com a arma da nossa temeridade.. Macabeus destemerosos subjulgando generais de Antíoco, com a lança do nosso destemor... Preferiamos considerar a humanidade e os fatos marionettes movidas pelo dedilhar instável das nossas transitórias concepções, a coñsiderá-los do ponto de vista da eternidade, como aconselhara Sprnosa... Sorríamos dos multifários óbices da existência, como Jasão despresara a violência das gláucas ondas, olhos postos no velocino de ouro da felicidade. . Saboreávamos apenas a ambrosia das vitórias fáceis que levam às ascensões e não conhecíamos o amargo do netar que os deuses manipulam para flagelar e ciliciar as vaidades...

Porque éramos no passado e transpuséramos de pouco os humbrais das misteriosas contradições da adolescência para ingressarmos nas desmedidas palpitações amorosas da mocidade.

Depois, a monotonia da disciplina escolar, com suas limitações e deveres, desceu-nos logo para o plano da realidade. Desfez-se o castelo de sonhos que imagináramos. A cornucópia de glórias transformou-se em casa de estudos severos, onde devíamos cumprir preceitos como os monges 
soíam cumprir na época em que fôra claustro. $O$ nosso lustro acadêmico sentiu todas as modificações que a nova ordem nacional operou no mundo jurídico. Iniciávamos a perslustração pelos bancos da Faculdade, quando a Carta Constitucional imprimiu diferente fisionomia política à Nação, procurando adequá-la a tendências e orientações de origem alienígena. A incoercível renovação dos conceitos jurídicos, devida a modernas idéias socializantes, veiu comprovar a verdade do ensinamento de Inering, de ser o Direito um constante e dinâmico vir-a-ser, alterando-se e modificando-se ao sabor das condições econômicas, psicológicas e morais dos povos. Imprescindivel fator da existência organizada e medula da vida social, o Direito nos apresentou cenários diversos criados pela desordenada evolução da Pátria. $O$ individualismo, cuja decadência fôra preanunciada no dealbar do século por Edmond PICARD em sua obra "O Direito Puro", cedeu posto ao direito social, compreendido como a colaboração nobre entre os indivíduos e destes com o Estado, para a sua realização teleológica, que é a felicidade da comunhão social. A solidariedade derribou o indivíduo-deus do pedestal em que o colocara o cataclisma revolucionário francês para substituí-lo pelo homem conciente e altruista, disposto a ceder prerrogativas acidentais em benefício da comunidade. $\mathrm{Na}$ recente codificação civil e penal substantiva como adjetiva, na aplicação exata da regra "rebus sic stantibus", na conceituação da propriedade como utilidade social, nas leis de proteção à família, na floração da atividade legiferante-trabalhista, no abandono do princípio rígido de justiça simplesmente punitiva, para adotar medidas de segurança preventivas e repressivas, verificamos estar o Direito Pátrio caminhando, a agigantados passos, para a substituição da fórmula igualitário-individualista pela de equiparação social, em obediência à diretriz socializadora, que GEORGEs RiPERT reconhece ser a única possivel de seguir nos tempos atuais. A socialidade do homem, admitida desde Aristóteles, não pode entretanto tirar ao Direito o carater individualista. Posto seja na 
essência sociaI, a natureza humana possue direitos imprescritiveis, que absolutamente independem de qualquer lei positiva. Baseados nesse princípio, que, entre outras, a cerebração privilegiada de VIctoR CATHREIN tão lúcidamente expõe nesse livro monumental que é "Philosophia Moralis", negamos fóros de cidadania às teorias extremas, nas quais o Estado absorve o indivíduo, ou este se coloca em posição de soberano, julgando-se um senhor que não deve obediência a leis e preceitos. Nossa legislação se carateriza por uma prudente moderação, pois foge das duas correntes antagônicas.

No presente, nossa geração não sorri, porque deve pensar. O universo está em dissolução, di-lo BERdaEFF. O direito é asselvajado pela fôrça, que o escraviza, quando devera tutelá-lo. A época é de eclipses... turva-se a razão humana no entrechoque estracinhante das carnificinas, que são, nesta antemanhã da nova Idade Média, o prelúdio lúgubre de uma sinfonia de lamentações. A civilização e a cultura, realizadas pela elaboração lenta das conquistas materiais e pela sedimentação dos conceitos, desaparecem sob escombros. Neste século da velocidade, que conta os quilômetros por segundos, o vento devastador que acompanha os pássaros mecânicos para fazê-los mais alígeros, apaga a lâmpada do progresso, destríuindo em minuto a frondosa árvore que veiu se robustecendo em milênios, nutrida pela genial cultura da Hélade, pela imensa organização jurídica romana, pelas excelsitudes do Cristianismo e pelas criações artísticas da Renascença. Säo Paulo, o apóstolo dos gentíos, afirmou só haver herança quando ha verdadeira morte. Da morte do século 19, que foi chamado o das luzes -, somos herdeiros da penumbra triste das cidades que se furtam à vista mortífera dos aviões. Nossa geração nasceu ouvindo o ressoar dos canhões da guerra européia, viveu-lhe os desastrosos efeitos e assiste, atônita e perplexa, à eclosão da maior hecatombe da história. A iminência de um conflito 
que exigirá a of erta do sangue em holocausto à estabilidade das instituições e à soberania da Nação, não nos permite veleidades líricas e sonhadoras. Somos uma geração preocupada e grave, que deve crer, mais do que as outras, na supremacia do espírito:

- para não desesperar do Direito e da Justiça, sob pena de engolfar-se nos abismos do agnosticismo...

- para não negar que somos seres pensantes, cuja longevidência espiritual leva-nos a medir os espaços astrais, atingindo o próprio Infinito...

- para não sorrir desdenhosamente de uma falsa arte que não tira estrêlas do cáos, procurando sublimar todas as tendências humanas de perfeição, mas condiciona a beleza a fórmas artificiais e desnaturantes...

- para não descrer da bondade e da fraternidade, nestes instantes em que Jahve não pune como outróra o pecado, enviando sôbre a terra o dilúvio e o fogo sôbre as cidades, mas permitindo que o homem destrua o homem. . - para não desacreditar da poesia, da família, da liberdade, da Pátria, de Deus, ante a alucinação sandia do engenho humano, que forja diabólicas construções bélicas para espesinhar povos livres e tripudiar, com o salto de ferro dos Césares conquistadores, sôbre as ruinas das catedrais.

Honra nos fazeis, senhor doutor Benedito Siqueira Ferreira, ao paraninfardes a nossa formatura. No convívio de três anos, durante os quais com autoridade pontificastes sôbre processo civil, soubestes dar, ao vosso ensino, marcante cunho de humanização. Com as vossas luminosas lições, amenizastes a fria exposição dos preceitos do código. A vossa cultura jurídica, reunis conhecimentos da arte médica. Médico sois, e homem do Direito... Não será porventura o jurista tambem terapeuta? Não lhe incumbe curar os males que afetam a sociedade, retirando do seu corpo o neoplasma horrendo do crime? Não exerce ele ver- 
dadeira medicina, cujo objetivo é expurgar e sanear a ordem pública? Sem dúvida, a medicina, cuja finalidade é a conservação da saude e cujo fundamento reside, segundo LiTTRÉ, na ciência das moléstias, a patologia, nasceu da necessidade de acudir o homem, sofredor físico. Cumpre ao jurista tratar a dor do homem, sofredor moral, quando lhe ferem a honra, a liberdade ou o patrimônio. Assim como não deve o médico limitar-se às abstrações da patologia, mas, como clínico, descer até a minudência analítica, filiando os casos singulares ao tipo mórbido previsto na sistemática nosológica, é missão do advogado retirar a lei da rigidez do código, vivificando-a pela aplicação justa ao caso concreto. Para o bom cumprimento desse apostolado, urge serem ambos bondosos. Durante vinte e quatro séculos, de Hrócrates a Corvisart, de Paracelsus a Miguel Couto, piedade e bondade têm sido o traço fundamental da mentalidade médica. Ambas marcam-se firmes na vossa personalidade, pois as rajadas do sofrimento e o trato com a desdita não sufocaram, em vossa alma, as manif estações nobres de comoção diante do infortúnio alheio. Duplo fundamento tem a admiração que vos dedicamos, senhor Professor: Porque, obedecendo aos preceitos do decálogo de Osvaldo Cruz, consagrais à fé eterna na ciência toda a sinceridade de vossa fé individual e honrais, pelo trabalho e pelo exemplo, o exemplo de trabalho que é a vossa vida. Vossa palavra, cujos acentos em breve far-se-ão ouvir, teve sempre unção respeitosa, porque compreendeis a finalidade que Ru atribuia ao magistério: "a hóstia, o arado, a palavra, correspondem aos três sacerdócios do Senhor; mas a suprema santificação da linguagem humana, abaixo da préce, está no ensino da mocidade."

Bacharelandos em 1941, bachareis em 1942, estamos no pórtico de saida da Academia. Como sóe acontecer em todos os momentos supremos, aguça-se a memória na recordação do que passou. $O$ olhar que se alonga pelo caminho 
andado, trái leves exteriorizações de melancolia. Nossa vida acadêmica de cinco anos está toda sintetizada nesta hora, em que parece haverem-se imobilizado os ponteiros do tempo, afim de mais indelevelmente gravarem-na no nosso sentimento.

A culminância em que nos encontramos engrandece o horizonte visual. $O$ pretérito projeta-se no presente e o ilumina, para descerrar os arcanos do porvir. Entre os mestres egrégios, credores da nossa gratidão, não podemos divisar de alguns sinão a presença constante do espírito. Durante o tempo acadêmico, a inexorabilidade do destino privou-nos a nós, à Academia e à Pátria, do talento e da cultura de Rafael Correia Sampaio, Manoel Pedro Vilaboím, José Augusto Cesar, Manoel Pagheco Prates e Alcântara MaCHADo, imortal no exemplo de sua vida, na perenitude granítica de sua obra e na saudade das gerações que lhe ouviram a palavra de mestre e amigo.

Somos privilegiados. Dos Professores desaparecidos, aposentados uns, licenciados outros, não recebemos durante o currículo a palavra direta e viva, sinão os conhecimentos buscados em seus escritos. Somos privilegiados, porque libertou-nos o fado da profecia pressaga de Alvares de AzEvEDo. O sopro gélido da morte não embaça o brilho das nossas festividades, nem seu manto cobre, com mortalha de nênias, as alelúias da nossa satisfação. Ãtropos, a deusa impiedosa, dileta favorita do Érebo e da Nioite, a nenhum cortou o fio da vida. . ou para que nossa alegria não se vestisse de luto, ou porque visse serem a nossa união e a nossa amizade tão indestrutíveis, que a própria separação da morte não conseguiria aniquilá-las.

0 ambiente de festa e de luzes testemunha a despedida da Academia. Ela nos acena o gesto largo e longo do adeus, solícita em vir dar-nos pela vez derradeira a última lição, 
os conselhos que a emoção no momento faz mal balbuciados:

- Não profaneis o templo da Justiça, mercadejando o Direito.

- Não useis da palavra, na cátedra, na tribuna, no pretório, sinão para defender o fraco contra a prepotência do forte, sinão para anatematizar o êrro e apostrofar a fráude.

- Não transformeis a vossa profissão em méro pretexto para locupletamentos.

- Não desvieis o rumo da Justiça ante as ameaças da fôrça ou as seduções do poder.

- Quando investidos da majestade olímpica de Juizes, não sejais como verdugos, agravando o rigor insensível das punições.

- Vivei sem tergiversações; quando a Pátria conclamar seus filhos para a defesa da sua dignidade ultrajada, sêde como vexilários, e cumprí a tradição de heroismo das Arcadas.

- Lembrai-vos que o ateismo não se compadece com o homem do Direito: Cristo é o fim da Lei, e não ha Justiça sem Deus.

- Imprimí à vossa luta o sentido nobre do sacrifício pelo Ideal e, como os apóstolos seguindo a exortação do Mestre Nazareno, diligenciai para vos aperceberdes das armas necessárias: "Qui non habet, vendat tunicam suam et emat gladium".

- Não permitais que, por pusilanimidade vossa, o Brasil seja compelido a curvar-se dolorosamente ante injunções estranhas. Tendes um dever sublime que será a coroa de louros da vossa geração e o seu martírio: empunhar a bandeira da honra nacional e ostentá-la sobranceiramente para que a felonia e a traição de estrangeiros, de dentro como de fóra, não vinguem na Pátria que é nossa, que é vossa, e de mais ninguem sinão de Brasileiros. 
Essa é, meus amigos e meus colegas, a voz da Academia : vinda do fundo dos seus centenários anos...

ouvida na terra piratiningana e ressoada pelos rincões todos da brasílica. .

confirmada pelo beneplácito de virtuosos cenobitas. . surgida, como iluminura, da névoa dos tempos...

nascida da austeridade respeitavel da fala dos mestres... brotada das estrofes luminosas dos seus poetas, que impregnaram as Arcadas das inspirações dos seus amores e das suas tristezas, das suas ilusões e das suas tragédias...

revestida do misticismo dos cânticos religiosos dos monges de S. Francisco e animada pelo entusiasmo primaveril da sua juventude...

ela é o* verbo coruscante da mocidade, que muita vez, como Cassandra prevenindo Príamo, como Loth admoestando os Sodomitas, sacudiu a conciência jurídica do Brasil para que não sucumbisse ele no opróbrio da inconstitucionalidade.

A dignidade do bacharelado, insígnia recebida em meio da alacridade de uma dispersão perfumada pelos enlevos afetivos da família e suavizada pelas congratulações dos entes queridos, seja para nós augúrio de um futuro auspicioso, subordinado à crença imarcessivel no bom, no justo e no honesto, que buscaremos sempre, como cintilações de rubí engastado no ostensório da Lei.

Narram os fastos do Livro Santo que Daví, após a vitória conseguida sôbre o Gigante, levou a sua espada ao tabernáculo, em devoto e grato of erecimento a Deus. Pelo suceder das vicissitudes, viu-se o profeta-rei necessitado de novos alentos para prosseguir na pugna contra os inimigos de Israel. Volta então ao tabernáculo e o Sumo Sacerdote lhe dá, com os pães santificados da proposição, a mesma espada que cortara a cabeça filistéia no Vale do Terebinto. 
Nas passagens emocionantes da luta incruenta pela Justiça, quando sentirmos que nos desfalece o ânimo, voltemos à Academia, - Tabernáculo do Direito -, e busquemos forças espirituais no Santuário da sua tradição. Veremos, em sugestiva romagem, a Academia e a Igreja comungando na mesma missão evangelizadora. Dois séculos antes de haver o douto Avelar Brotero proferido na sacristia do monastério a "Oração da Sapiência", segundo as usanças da Universidade Conimbricense, as mãos frias e magras de um monge trabalham o sáibro, a táipa e o humus da terra paulista, para edificar uma habitação destinada à vida religosa...

$$
\begin{array}{llllllllllll}
\ldots & \ldots & \ldots & \ldots & . & \ldots & \ldots & \ldots & \ldots & \ldots & \mathrm{E} & \ldots \\
\text { vós, }
\end{array}
$$

Frei Francisco das Neves, custódio da Ordem Seráfica de São Francisco de Assis, quando plantastes em 1643, no alto da colina de Piratininga, o germe do monumento estilo barroco-jesuítico-século XVIII, que recorda a arte aprimorada de Luiz XV e Bernini, de Churriguera e D. Joũo V, não teríeis rezado a Deus, naquele dilúculo brumoso da História de São Paulo, não teríeis rezado Frei Francisco, para que Deus désse ao corpo físico do convento uma alma, a alma vibrante e imortal da mocidade, e uma conciência - A CONCIENCIA JURÍDICA DA NAÇÃO? 